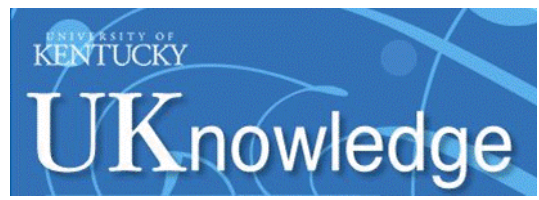

University of Kentucky

UKnowledge

Preventive Medicine and Environmental Health

Faculty Publications

Preventive Medicine and Environmental Health

3-1-2017

\title{
Sensemaking, Stakeholder Discord, and Long-Term Risk Communication at a US Superfund Site
}

Anna Goodman Hoover

University of Kentucky, anna.hoover@uky.edu

Follow this and additional works at: https://uknowledge.uky.edu/pmeh_facpub

Part of the Environmental Public Health Commons, and the Health Communication Commons

Right click to open a feedback form in a new tab to let us know how this document benefits you.

\section{Repository Citation}

Hoover, Anna Goodman, "Sensemaking, Stakeholder Discord, and Long-Term Risk Communication at a US Superfund Site" (2017). Preventive Medicine and Environmental Health Faculty Publications. 49.

https://uknowledge.uky.edu/pmeh_facpub/49

This Article is brought to you for free and open access by the Preventive Medicine and Environmental Health at UKnowledge. It has been accepted for inclusion in Preventive Medicine and Environmental Health Faculty

Publications by an authorized administrator of UKnowledge. For more information, please contact

UKnowledge@lsv.uky.edu. 


\title{
Sensemaking, Stakeholder Discord, and Long-Term Risk Communication at a US Superfund Site
}

\author{
Digital Object Identifier (DOI) \\ https://doi.org/10.1515/reveh-2016-0048 \\ Notes/Citation Information \\ Published in Reviews on Environmental Health, v. 32, issue 1-2, p. 165-169. \\ (C2017 Walter de Gruyter GmbH, Berlin/Boston.
}

The copyright holder has granted the permission for posting the article here. 
Anna Goodman Hoover*

\section{Sensemaking, stakeholder discord, and long-term risk communication at a US Superfund site}

DOI 10.1515/reveh-2016-0048

Received August 26, 2016; accepted December 13, 2016

\begin{abstract}
Introduction: Risk communication can help reduce exposures to environmental contaminants, mitigate negative health outcomes, and inform community-based decisions about hazardous waste sites. While communication best practices have long guided such efforts, little research has examined unintended consequences arising from such guidelines. As rhetoric informs stakeholder sensemaking, the language used in and reinforced by these guidelines can challenge relationships and exacerbate stakeholder tensions.
\end{abstract}

Objectives: This study evaluates risk communication at a U.S. Superfund site to identify unintended consequences arising from current risk communication practices.

Methods: This qualitative case study crystallizes data spanning 6 years from three sources: 1) local newspaper coverage of site-related topics; 2) focus-group transcripts from a multi-year project designed to support future visioning of site use; and 3) published blog entries authored by a local environmental activist. Constant comparative analysis provides the study's analytic foundation, with qualitative data analysis software QSR NVivo 8 supporting a three-step process: 1) provisional coding to identify broad topic categories within datasets, 2) coding occurrences of sensemaking constructs and emergent intra-dataset patterns, and 3) grouping related codes across datasets to examine the relationships among them.

Results: Existing risk communication practices at this Superfund site contribute to a dichotomous conceptualization of multiple and diverse stakeholders as members of one of only two categories: the government or the public. This conceptualization minimizes perceptions of capacity, encourages public commitment to stances aligned with a preferred group, and contributes to negative expectations that can become self-fulfilling prophecies.

\footnotetext{
*Corresponding author: Anna Goodman Hoover, PhD, Department of Preventive Medicine and Environmental Health, University of Kentucky College of Public Health, 111 Washington Ave., 203b, Lexington, KY 40536, USA, E-mail: Anna.Hoover@uky.edu
}

Conclusion: Findings indicate a need to re-examine and adapt risk communication guidelines to encourage more pluralistic understanding of the stakeholder landscape.

Keywords: environmental communication; hazardous waste sites; sensemaking; seven cardinal rules.

\section{Introduction}

In the mid-1980s, several high-profile environmental crises highlighted the need for government agencies and industry to better inform citizens about exposure-related health risks (1-4). In response, the risk communication field emerged to develop strategies for sharing hazard-related information with lay populations. Among the field's first products was the U.S. Environmental Protection Agency's (U.S. EPA) Seven Cardinal Rules of Risk Communication (5), which provided recommendations later adapted and deployed by other agencies (6-8). While these guidelines improved on the sparse risk communication efforts that preceded them (9), their sustained use over time necessitates examination of their long-term impacts on sensemaking (10), the interactive and situated way in which individuals jointly create shared meaning (11). An ongoing process, sensemaking helps people understand risk and shape their environments, which then constrains future choices and actions $(12,13)$.

This qualitative case study applies sensemaking theory in a long-term risk communication setting to answer the research question, "How does long-term enactment of risk communication guidelines influence stakeholder understandings of roles, responsibilities, and actions in a complex policy context?" While constrained in scope and generalizability, such a context-driven case analysis can contribute important and transferable lessons-learned for similar settings while also beginning to address knowledge gaps regarding the real-world effects of guidelines and best practices over time. Focusing on discourse related to western Kentucky's Paducah Gaseous Diffusion Plant (PGDP), a National Priorities List (NPL) Superfund site, this study examines multiple datasets to better understand how myriad communication activities across three decades have affected the three mediators that constrain sensemaking: 1) capacity, which restricts 
the number and diversity of potential sensemakers; 2) commitment, which contributes to formation of "blind spots" in the "tenacious justification" of particular positions; and 3) expectations, which generate assumptions that become "self-fulfilling prophecies" (10). To explore these issues, however, first requires explication of the case context.

\section{Superfund, Risk Communication, and the PGDP}

The Comprehensive Environmental Response, Compensation, and Liability Act of 1980, or Superfund, provided for long-term investigation and remediation of hazardous waste sites, creating a National Priorities List (NPL) to guide regulatory agencies (14). Within the decade, additional federal legislation strengthened state and local involvement in site-related planning and decisions (15). As the diversity of stakeholders guiding site decisions grew, so grew the need for timely, clear, and accurate risk communication. In 1988, Seven Cardinal Rules emerged to provide guidance in a variety of areas, urging practitioners to be credible and compassionate, develop partnerships, evaluate communications, and "listen to the public's specific concerns" (5).

Statutory complexity and stakeholder diversity render Superfund communities particularly challenging environments for enacting these Rules, however. By federal law, the U.S. EPA oversees Superfund clean-up activities, while the Agency for Toxic Substances and Disease Registry (ATSDR) investigates site-related public health impacts (15). Additionally, the U.S. Department of Energy (U.S. DOE) is responsible for clean-up of 21 Superfund sites (16), with both the scale of its environmental management efforts and revelations of prior waste mismanagement (17) contributing to stakeholder distrust of the agency (18-20).

The PGDP exemplifies these challenges. A former U.S. DOE uranium enrichment facility, PGDP joined the NPL after the 1988 discovery of trichoroethylene and technetium-99 in private drinking wells near the plant. Consequently, the PGDP community - which comprises plant employees, residents nearby, and multiple public entities and private individuals with stakes in economic development, environmental protection, and/or the health and well-being of the local populace - has received decades of risk information from federal, state, and local agencies, universities, and advocacy groups. Such information has focused on a wide range of topics, from informing community members about risk to helping former employees and their families understand and navigate federal compensation processes to discussing the potential for federal acquisition of properties near the PGDP.

In Paducah, complex relationships have developed through decades of such discussions about the plant, its role(s) in the community, and the potential economic, health, and environmental consequences of its presence in the region. Thus, numerous constituencies with varied levels of technical knowledge and emotional investment have shared information with each other. From this information and guided by prior events and understandings, stakeholders attempt to understand site-related risks. Despite years of information flows, many local stakeholders have expressed distrust of such information, citing government agencies and the U.S. DOE in particular as untrustworthy (21). Such ongoing credibility concerns raise questions about how more than a quarter-century of risk communication activities have informed stakeholder relationships and sensemaking.

\section{Methods}

This study crystallizes data from three sources spanning 6 years (2005-2011) that together present diverse perspectives about the plant. First, local newspaper coverage of PGDP-related topics was analyzed for calendar year 2005, a period during which public information exchanges were necessitated by such high-profile events as: 1) transfer of sick worker health benefits administration from the U.S. DOE to the US Department of Labor; 2) public release of a federal report on employee radiation exposure at the plant; 3) negotiation of new environmental cleanup subcontracts; and 4) Department of Homeland Security drills. Analysis of the 364 daily archived editions available yielded 85 PGDP-related articles.

Secondly, focus group transcripts were analyzed from a 20102011 project designed to help identify stakeholder values and preferences related to the final disposition of the PGDP site following the plant's anticipated closure. Eight focus group sessions deployed purposive sampling to convene individuals with similar commitments and perspectives: 1) PGDP employees; 2) U.S. DOE employees and subcontractors; 3) residents near the plant who receive municipal water at U.S. DOE expense; 4) civic leaders from an adjacent county; 5) environmental and health advocates; 6) economic development and local government leaders; 7) hunting, wildlife, recreation, and tourism enthusiasts; and 8) healthcare professionals and educators. Among the 64 adults who participated in one of these focus groups, 44 were male and 20 female.

The third data source consisted of public blog entries written by a local environmental activist who had been dissatisfied with his participation in one of the focus groups, as well as with the overall project. Using his blog as a forum, he wrote extensively about his perception of the events that transpired during the focus group and in the months that followed. A total of nine blogs were analyzed, providing key information regarding how this participant made sense of the research team, the project, and the focus group itself through the lens of past interactions with other site stakeholders. 
Qualitative data analysis software QSR NVivo 8 supported textual analysis $(22,23)$ through a three-step process. This process began with provisional coding of each dataset independently to identify broad topic categories, followed by coding occurrences of sensemaking constructs and emergent intra-dataset patterns before grouping related codes across datasets to examine the relationships among them (24). Constant comparative methods $(25,26)$ provided the analytic foundation, with cycles of data coding that involved repeated comparison of data to extant literature to initial conclusions and back to data (27-29).

\section{Limitations}

Case study research focuses on understanding rather than prediction and is bounded by geographic, temporal, and sociopolitical dimensions. While findings are not generalizable, insights may be transferrable to similar settings and circumstances $(30,31)$. The inclusion of multiple datasets, extensive participant-observer field notes, and member checks of preliminary results are intended to support informed assessments of validity and transferability to similar settings and situations (26).

\section{Results}

Discourse about the PGDP often relies on dichotomous terminology dividing stakeholders into two camps: 1) The Government and 2) The Public. These groupings conflate roles and responsibilities among site-related actors, downplaying the variety of perspectives about and stakes in the site. This division appears across news coverage, focus groups, and local blogs.

Newspaper content analysis of 85 articles identified 21 instances of the conflation of multiple agencies into The Government, often related to coverage of a worker compensation program that had changed management. In one article, a journalist responded to suspicions that employee illnesses were exposure-related with, "Now the government confirms it" (32). With the U.S. DOE, the National Institute of Occupational Safety and Health, and the U.S. Department of Labor playing distinct roles in various aspects of the transition, the journalist's assertion about "the government" presented a tidy but oversimplified depiction of the situation. A subsequent article included a deceased worker's family member stating that "the government is trying to get out of paying what it owes" (33), implying that all agencies were working toward a clearly defined, shared goal of disadvantaging sick workers.

Such framing also was problematic when distrust of the U.S. DOE extended to distrust of all governmental entities. When stakeholders in focus groups were asked to name credible sources for PGDP-related information, many stated flatly that the U.S. DOE was not credible. Use of "The Government" expanded that distrust to encompass other agencies. As one participant noted, "I would not want [information from] anybody affiliated with the government in any way".

While many local stakeholders saw a credibility deficit for The Government, focus groups with technical experts saw agency staff and plant employees often using the term "The Public" to describe those stakeholders perceived as having a technical knowledge deficit. One worker reminded researchers that they were not talking to the public [because] "the general public still has a very vague idea of what's out here". Explaining that the erroneous "general consensus" was that site contamination was on par with a nuclear power plant, he noted, "No matter what scenario you go with, that's going to "be a factor with the general public". Thus, the employee not only separated himself and his colleagues from The Public, but he also implicitly defined The Public as a group that clings to misinformation in the face of technical facts. Such statements indicate a blind spot the employee had regarding the (in)ability of The Public to understand and interpret relevant risk information.

In contrast, stakeholders who self-identified as The Public saw themselves as targets of manipulation by The Government. In evaluating one hypothetical scenario for the site's future, a focus group participant stated that it seemed like "one of the easier ones "for the public to swallow", while a local business leader remarked that another scenario would be "a tough sell for the public". Thus, while The Public is depicted as playing a passive role, it also is seen as vulnerable to persuasion under certain circumstances.

For one local blogger, the ability to define membership in The Public was important. Reporting that he had requested a list of study "advisory board" members, he noted that he was certain it consisted of "a bunch of names of 'influential' folks", further stating that, "it's important for the public to know" the membership roster (34). These statements support a vision of "influential" members of the community - often the gatekeepers with whom risk communicators partner - as outside, rather than members of, The Public.

\section{Discussion}

In Paducah, plant-related discourse surrounding The Government and The Public creates a rhetorical binary $(35,36)$ that implies only two possible identities exist, 
thus reducing sensemaking capacity and limiting the perceived range of choices and perspectives. This constraint complicates information exchange, as individuals categorize messages, activities, perspectives, and motives within one of the two categories reflected in the Seven Cardinal Rules approach: an agency helping a public fill information gaps. At long-term risk sites, however, multiple organizations address diverse stakeholders through statements, press releases, and public meetings, often over a period of decades. When all agencies are included in the monolithic The Government, the perceived number of actors is greatly reduced, roles and responsibilities become muddied, and expectations based on one agency's prior actions drive assumptions about another's current actions. Thus, stakeholders who view all members of The Government as representing a lone, distinct perspective may expect little benefit from engaging multiple agencies.

The second term in the binary, The Public, is codified in Seven Cardinal Rules, with the phrase appearing nine times in the two-page document. When diverse organizations and individuals are grouped as the monolithic The Public, sensemaking capacity again is challenged by a reduction in the perceived number of distinct actors and sometimes conflicting viewpoints. Thus, agency officials and others who view The Public as representing a lone, distinct perspective may expect little benefit from engaging these diverse groups and individuals.

In addition to decreasing capacity, the binary promotes adversarial relationships by underscoring differences and marginalizing stakeholders. Through the othering process (37), in which people classify some individuals or groups as being entirely different from themselves, stakeholders commit to one of two available identities and judge the other's merit based on its opposition to self. Paducah provides numerous examples of othering, with The Government frequently described as slow, bureaucratic, and/or secretive, while The Public is depicted as lacking technical knowledge, the ability to adequately apply technical information to decision-making, and/or a level of control that would permit real influence on governmental decisions. Commitment to one of these identities thus contributes to blind spots about the motivations, statements, and actions of other stakeholders, as well as to tenacious justifications of one's own beliefs and opinions.

\section{Conclusion}

By implementing sensemaking theory as a diagnostic tool, this study identifies communication challenges in one chronic risk community. For decades, the U.S. EPA's Seven Cardinal Rules and other best practices have played important roles in how site stakeholders discuss and understand risk. While related evaluations often focus on assessing knowledge and/or attitude change, it also is important to examine the effects of risk communication on site relationships.

To address the communicative and relational challenges described, a reconceptualization of risk communication is needed that transitions from guidelines focused on The Public and The Government to acknowledge explicitly the diversity of stakeholders involved in site-related decisions, thereby increasing capacity, reducing the likelihood of intransigent commitments, and improving expectations for communication and collaboration. Subsequent revised risk communication guidelines could promote shared sensemaking while mitigating adversarial interactions that contribute to the formation of blind spots. Over time, such changes could improve capacity for sensemaking across constituencies, creating a more positive framework within which diverse stakeholders can collaborate to mutually assess risk and make decisions.

Acknowledgments: The author thanks the citizens of McCracken and Ballard Counties who participated in focus groups; dissertation director Chike Anyaegbunam, Ph.D., and committee members Timothy L. Sellnow, Ph.D., H. Dan O'Hair, Ph.D., and Lisa Gaetke, Ph.D.; as well as Lindell Ormsbee, Ph.D.; and the University of Kentucky Superfund Research Program Research Translation Core.

\section{Author Statement}

Research Funding: Primary data collection described herein was supported by grant number DE/FG05030R23032 from the United States Department of Energy. Data analysis was conducted in conjunction with grant number P42 ES007380 from the National Institute of Environmental Health Sciences, NIH. Conflict of Interest: Author states no conflict of interest. The contents of this manuscript are solely the responsibility of the author and do not necessarily represent the official views of the NIEHS, NIH or USDOE. Informed Consent: This study relies on analysis of both primary focus group data and secondary public data sources. During primary data collection, informed consent was obtained from all participants. Ethical Approval: Primary data collection was conducted with guidance and approval of the University of Kentucky Institutional Review Board (Protocol \#10-0086-P4S). 


\section{References}

1. Perrow C. Normal accidents. New York: Basic Books, 1984.

2. Shrivstava P. Bhopal: anatomy of a crisis. New York: Ballinger (Harper Collins), 1987.

3. Palenchar MJ, Heath RL. Strategic risk communication: adding value to society. Public Relat Rev 2007;33(2):120-9.

4. NRC. Improving risk communication. Washington, D.C.: National Academies Press, 1989.

5. Covello VT, Allen FW. Seven cardinal rules of risk communication. Washington. D.C.: U.S. EPA, 1988.

6. ATSDR. A primer on health risk communication principles and practices. CDC, 1994. Available at: http://www.atsdr.cdc.gov/ risk/riskprimer/vision.html.

7. Tinker TL. Recommendations to improve health risk communication: lessons learned from the U.S. Public Health Service. J Health Commun 1996;1:197-217.

8. Adler PS, Karnowitz JL. A primer on perceptions of risk, risk communication, and building trust. Keystone, $\mathrm{CO}$ : The Keystone Center, 2005.

9. Covello VT, Sandman PM. Risk communication: evolution and revolution. In: Solutions to an environment in peril. Baltimore, NJ: Johns Hopkins University Press, 2001:164-78.

10. Weick K. Enacted sensemaking in crisis situations. J Manage Stud 1988;25(4):305-17.

11. Blumer H. Sociological implications of the thought of George Herbert Mead. Am J Sociol 1966;71(5):535-48.

12. Weick KE. Sensemaking in organizations. Thousand Oaks, CA: Sage, 1995.

13. Weick KE. The collapse of sensemaking in organizations: the Mann Gulch disaster. In: Weick KE, editor. Making sense of the organization. Oxford: Blackwell Publishers, Inc., 2001:537-50.

14. US EPA. Superfund: National Priorities List. 2016. Available at: https://www.epa.gov/superfund/superfund-national-prioritieslist-npl.

15. US EPA. Superfund: Cleanup process. 2011. Available at: http:// www.epa.gov/superfund/cleanup/index.htm.

16. US DOE. Office of environmental management: projects. 2011. Available at: http://www.em.doe.gov/Pages/projects.aspx.

17. Bruce AS, Becker PJ. State-corporate crime and the Paducah Gaseous Diffusion Plant. West Criminol Rev 2007;8(2):29-43.

18. Taylor BC, Kinsella WJ, Depo SP, Metzler MS. Nuclear legacies: communication, controversy, and the U.S. nuclear weapons production complex. In: Communication Yearbook. Malwah, NJ: Lawrence Erlbaum Associates, 2005;29:363-409.
19. Flynn J, Slovic P, Mertz CK, Toma J. Evaluations of Yucca Mountain: survey findings. Carson City, NV: 1990 NWPO-SE-029-90.

20. Slovic P. The perception of risk. London: Earthscan Publications Ltd., 2000.

21. KRCEE. Community visions for the Paducah Gaseous Diffusion Plant. Lexington, KY: University of Kentucky, 2011 Contract No.: P25.1 2011.

22. Furisch E. In defense of textual analysis: restoring a challenged method for journalism and media studies. Journalism Stud 2009;10(2):238-52.

23. Stern B. Textual analysis in advertising research: construction and deconstruction of meaning. J Advert Res 1996;25(3):61-73.

24. Saldaña J. The coding manual for qualitative researchers. Thousand Oaks, CA: Sage, 2015.

25. Strauss AL. Qualitative analysis for social scientists. Cambridge: Cambridge University Press, 1987.

26. Butler-Kisber L. Qualitative inquiry: thematic, narrative, and arts-informed perspectives. Los Angeles, CA: Sage, 2010.

27. Ellingson L. Engaging crystallization in qualitative research: an introduction. Los Angeles, CA: Sage, 2009.

28. Strauss A, Corbin J. Basics of qualitative research. Newbury Park, CA: Sage, 1990.

29. Charmaz K. Constructivist and objectivist grounded theory. In: Handbook of qualitative research. Thousand Oaks, CA: Sage, 2000;2:509-35

30. Guba, EC. Criteria for assessing the trustworthiness of naturalistic inquiries. Educ Comm Tech J 1981;29(2):75-91.

31. Baxter JW, Eyles JD. The utility of in-depth interviews for studying the meaning of environmental risk. Prof Geog 1999;51:307-20.

32. Walker J. Compensating sick workers: cancer victim finally nears settlement in plant exposure. Paducah Sun. 2005.

33. Walker J. Coverage sought for all children of sick workers. Paducah Sun. 2005

34. Donham M. Rural thoughts [Internet]. Paducah. KY. 2010. [cited 2012]. Available at: http://www.ruralthoughts.net/index. php?q=node $/ 415$.

35. McCarthy C, Demitriades G. Governmentality and the sociology of education: media, educational policy, and the politics of resentment. Br J Sociol Educ 2000;21(2):169-85.

36. Clarke AE. Situational analysis: grounded theory after the postmodern turn. Thousand Oaks, CA: Sage, 2005.

37. Johnson, JL, Bottorff JL, Browne AJ, Grewal S, Hilton BA, Clarke $\mathrm{H}$. Othering and being othered in the context of health care services. Health Commun 2004;16(2):253-71. 